\title{
Iron mobility in slab-derived hydrous silicate melts at sub-arc conditions
}

\author{
CARLA TIRABOSCHI ${ }^{1}$, ARNO ROHRBACH ${ }^{1}$, STEPHAN \\ KLEMME $^{1}$, JASPER BERNDT ${ }^{2}$ AND CARMEN SANCHEZ- \\ VALLE $^{1}$ \\ ${ }^{1}$ Universität Münster \\ ${ }^{2}$ University of Münster \\ Presenting Author: ctirabos@uni-muenster.de
}

Aqueous and saline fluids have a fundamental role in subduction zones and represent a major vector of mass transfer from the slab to the mantle wedge. In this setting, assessing the mobility of redox sensitive elements, such as iron, in aqueous fluids and melts is essential to provide insights on the oxygen fugacity conditions of slab-derived fluid and the oxidation state of arc magmas.

We experimentally investigate the solubility of magnetite and hematite in water-saturated haplogranitic liquids, which represent the felsic melt produced by subducted eclogites. Experiments were conducted at 1-2 GPa and temperature ranging from 700 to $900{ }^{\circ} \mathrm{C}$ employing an endloaded piston cylinder apparatus. Single gold capsules were loaded with natural hematite, magnetite and synthetic haplogranite glass. Two sets of experiments were conducted: a first set with pure $\mathrm{H}_{2} \mathrm{O}$ and a second set with a $1.5 m \mathrm{H}_{2} \mathrm{O}-\mathrm{NaCl}$ solution. After quench, the presence of $\mathrm{H}_{2} \mathrm{O}$ in the haplogranite glass was checked by Raman spectroscopy, while iron and major element contents were determined by electron microprobe analysis.

Results show that a significant amount of $\mathrm{FeO}$ is released from magnetite and hematite equilibrated with hydrous melts, up to $1.82 \pm 0.11 \mathrm{wt} \%$ at $1 \mathrm{GPa}$ and $900{ }^{\circ} \mathrm{C}$. In the presence of $\mathrm{NaCl}$, we observed an increase in the amount of iron in the haplogranite glass, e.g. from $1.04 \pm 0.12 \mathrm{wt} \%$ to $1.50 \pm 0.31 \mathrm{wt} \%$ of $\mathrm{FeO}_{\text {tot }}$ at $800{ }^{\circ} \mathrm{C}$. These concentrations are substantially larger than the iron solubility in aqueous saline fluids predicted by thermodynamic modelling (DEW model [1]), likely due to formation of $\mathrm{Fe}$ - and Si-bearing complex in the haplogranitebearing fluid at run conditions. Our results suggest that hydrous melts can effectively mobilize iron from Fe-oxides even at lowpressure conditions. Slab-derived hydrous melts can thus represent a valid agent for mobilizing iron from the subducting slab to the mantle wedge, and can strongly influence the geochemical cycles of $\mathrm{Fe}$ and the redox conditions of subduction zone fluids.

[1] Sverjensky, Harrison \& Azzolini (2014). Geochim. Cosmochim. Acta 129, 125-145. 